\title{
Synthesis of Mesoporous TS-1 for Catalytic Oxidative Desulfurization
}

\author{
Chul-Woo Park, Tae-Kyung Kim, and Wha-Seung Ahn' \\ Department of Chemical Engineering, Inha Unwersity Incheon 402-751, Korea \\ E-mail: whasahnatima.ac.kr \\ Received Mav 18, 2009. Accepted June 25, 2009
}

\begin{abstract}
Mesoporous TS-I catalysts were prepared via a nanocasting route using two different carbon template sources of CMK-3 and conmercial carbon black. Products were characterized by XRD, UV-Vis spectroscopy, SEM, TEM, and $\mathrm{N}_{2}$ adsorption-desorption measurement. The catalytic perfomances of the samples for allylohloride epoxidation and oxidative desulfurization of the representative refractory sulfur compounds, dibenzothiophene and 4,6-dimethyldibenzothiophene, were compared against those of conventional TS-1. Whilst the allychloride epoxidation activity for the mesoporus TS-1 samples were similar, mesoporous TS-l exhibited significantly higher catalytic activities than conventional TS-l in oxidative desulfurization.
\end{abstract}

Key Wonds: Mesoporous TS-1. CMK-3, Carbon black, Oxidative desulfurization

\section{Introduction}

Sulfur removal in transportation fuels is necessary in order to reduce the pollution level in the atmosphere, and currently ultra-deep desulfurization of fuel oil is receiving a worldwide attention ever since the announcement of the stringent $U$. $S$. environmental regulations imposed. limiting the sulfur level in diesel to $<15$ ppmw. ${ }^{1.2}$ The most common industrial process for desulfurization is the treatment of the fuel with hydrogen at high temperature and high pressure conditions. ${ }^{3}$ Whilst this conventional hydrodesulfurization (HDS) is highly efficient in removing thiols, sulfides. and disulfides. ${ }^{4}$ the HDS process to achieve ultra-deep desulfurization of diesel requires increasingly severe operating conditions with high consumption of hydrogen, thus incurring a penalty of significant capital expenditure. Obviously, development of an alternative desulfurization process is desirable, and now oxidative desulfurization (ODS) under mild conditions (atmospheric pressure and temperature lower than $80^{\circ} \mathrm{C}$ ) is being considered as one of the most promising options for the ultra-deep desulfurization. ${ }^{6 ?}$

For ODS. Ti-containing zeolites have been extensively investigated as catalyst because of their outstanding oxidation property and utilization of peroxides having an environmentally benign nature as oxidant. ${ }^{8-1(1}$ It is known that some small sulfides such as mercaptan, thioether, even thiophene, a highly stable organic sulfide can be effectively oxidized by TS-I catalyst. " However. conventional microporous TS-1 shows poor catalytic activity in the oxidation of bulkier sulfur compounds such as dibenzothiophene (DBT) and its derivatives, due to intracrystalline diffusion limitations imposed by small pores. Therefore efforts have been made to resolve this diffusion limitation problem in TS-1 by introducing mesopores, and various template synthesis techniques that enable a preparation of zeolites having mesopores have newly emerged. In particular. much attention has been given to the synthesis of mesopore-containing zeolites via nanocasting by employing various sacrificial carbon templates in the hydrothermal synthesis of zeolites.
In this work. we conducted a systematic comparison of the synthesis routes for making mesoporous TS- 1 , and detailed characterization of the mesoporous TS-1 zeolites prepared by employing two different carbon templates (carbon black and $\mathrm{CMK}-3$ ) was reported. We carried out a probe reaction of allychloride epoxidation using $\mathrm{H}_{2} \mathrm{O}_{2}$ as oxidant to confirm the nature of catalytic Ti sites in all the TS-l samples prepared. Finally, it was demonstrated that the mesoporous TS-1 samples exhibit superior catalytic performances in oxidative desulfurization of selected bulky sulfur compounds to conventional TS-1, which were also influenced by the property of the carbon template used.

\section{Experimental}

Synthesis of mesoponous TS-1. For the synthesis of mesoporous TS-1, CMK-3 and carbon black (N762. Degussa) were used as solid template. SBA-15 was prepared following the literature procedure reported earlier. ${ }^{18}$ and the calcined SBA-15 was then used as tenulate for making CMK-3. CMK-3 was prepared according to the literature procedure. ${ }^{19}$ The CMK-3 produced had the BET area of $1070 \mathrm{~m}^{2} \mathrm{~g}^{.1}$ and the total pore volume of $1.1 \mathrm{~cm}^{3} \mathrm{~g}^{-1}$. N762 has, on the other hand. had the BET area of $12+\mathrm{m}^{2} \mathrm{~g}^{-1}$ and the total pore volume of $0.22 \mathrm{~cm}^{3} \mathrm{~g}^{-1}$. The carbon black consists of nearly spherical primary particles with typical diameters ranging from 20 to $150 \mathrm{~nm}$.

Mesoporous TS-1 was prepared following the dry gel synthesis procedure reported by Jacobsen et al. ${ }^{\text {if }} \mathrm{CMK}-3(\mathrm{l} .0 \mathrm{~g})$ or carbon black $(4.0 \mathrm{~g})$ was impregnated with a clear solution containing tetrapropylammonium hydroxide (TPAOH. $40 \mathrm{wt} \%$. TCI $3.3 \mathrm{~g}$ ) and ethanol (3.3 g). After evaporating ethanol at $40^{\circ} \mathrm{C}$, a mixture of tetraethylorthosilicate (TEOS. $98 \mathrm{wt} \%$, Aldrich) and tetrabuty lorthotitanate (TBOT. 97 wt\%. Aldrich) was added with incipient wetness. The molar conposition of the resulting synthesis gel was kept to $20 \mathrm{TPA}_{2}: \mathrm{TiO}_{2}: 100 \mathrm{SiO}_{2}$ : $200 \mathrm{H}_{2} \mathrm{O}$. The gel was transferred into a Teflon liner containing sufficient water to produce saturated stean. The liner was placed inside a stainless steel autoclave and heated at $170{ }^{\circ} \mathrm{C}$ 
for $72 \mathrm{~h}$. After the hydrothermal reaction. the autoclave was quenched in cold water and the powder was recovered by filtration and washed with de-ionized water. The final powder was calcined in air at $550^{\circ} \mathrm{C}$ for $8 \mathrm{~h}$ to remove the organic structure-direction agent. For comparison. a conventional microporous TS- 1 with similar titanium content synthesized according to Ref. 20.

Characterization The crystallinity of the samples prepared was measured by X-ray diffraction using CuKa radiation (Phillips. PW-1700). Nitrogen adsorption-desorption isotherms were measured using a Micromeritics ASAP-2020 instrument at $77 \mathrm{~K}$. UV-Visible spectra were obtained under ambient conditions using dehydrated $\mathrm{MgO}$ as a reference in the range of $190-500 \mathrm{~nm}$ on a Varian CARY-3E double beam spectrometer. Scanning electron microscopy (SEM) was performed using Hitachi \$-4300 electron microscope. and transmission electron microscopy (TEM) measurements were taken on a Philips CM200.

Catalytic study. Allylchloride epoxidation using $\mathrm{H}_{2} \mathrm{O}_{2}(30$ $w t \%$. Aldrich) as oxidant was performed using Chemistation

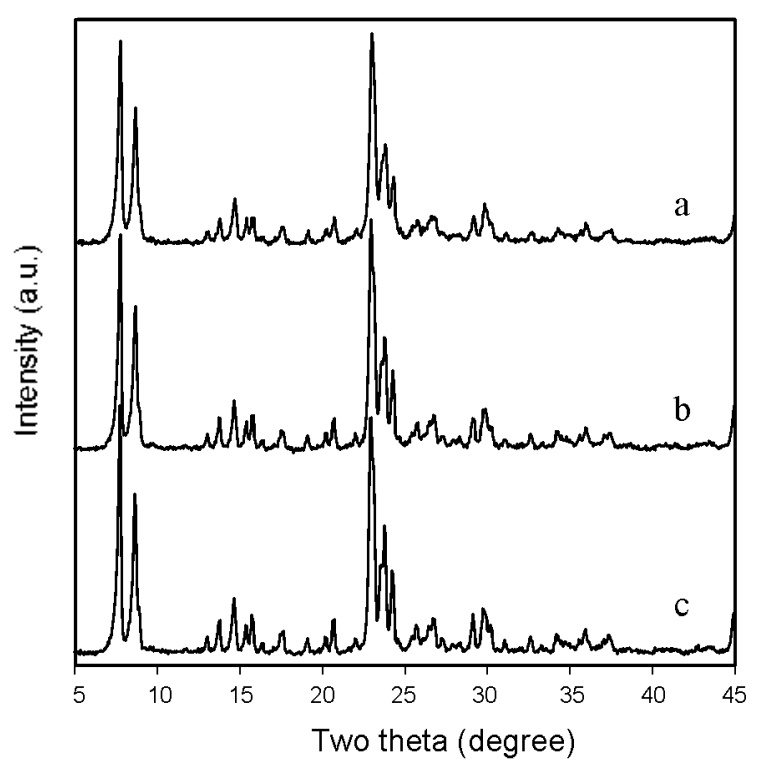

Figure 1. XRD patterns of (a) TS-1 synthesized with CMK-3, (b) TS-1 synthesized with carbon black, and (c) conventional TS-1.

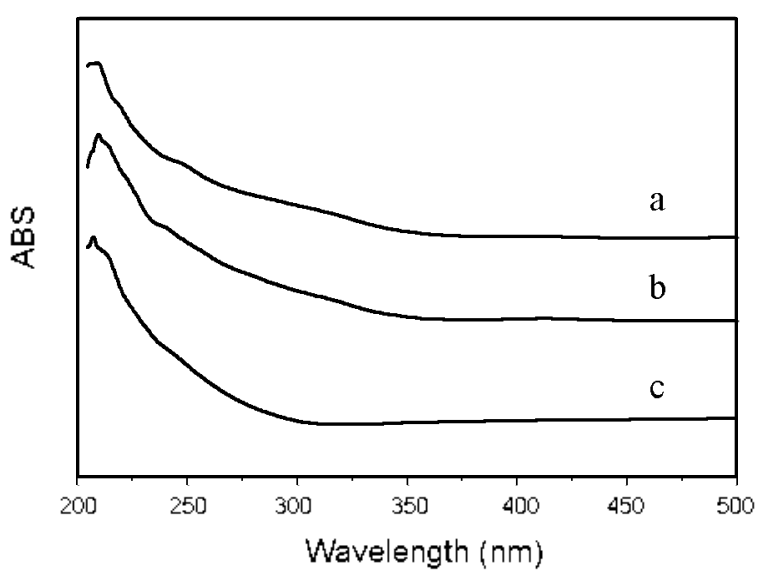

Figure 2. UV-Vis spectra of (a) TS-1 synthesized with CMK-3, (b) TS-1 synthesized with carbon black, and (c) conventional TS-1.
PPS-2510 fitted with a condenser (Eyela). The reaction was carried out at $318 \mathrm{~K}$ for $2 \mathrm{~h}$ using $32 \mathrm{mmol}$ substrate. $17 \mathrm{mmol}$ $\mathrm{H}_{2} \mathrm{O}_{2} 20 \mathrm{~mL}$ methanol. and $0.15 \mathrm{~g}$ catalyst under vigorous stiming. The products were analyzed by using a gas cluromatography (HP5890 series II GC). The concentration of $\mathrm{H}_{2} \mathrm{O}_{2}$ after a reaction was determined by $0.1 \mathrm{M}$ cerium sulfate titration using ferroin indicator.

The ODS reactivity of model sulfur compounds was studied in a $100 \mathrm{~mL}$ glass batch reactor equipped with a temperature controller. a condenser. and mechanical stirrer. Typically. $48 \mathrm{~g}$ of feed ( $n$-heptane $80 \mathrm{w} \%$ and toluene $20 \mathrm{wt} \%$ ) containing model sulfur compounds of $200 \mathrm{ppmw}$-S with a molar ratio of tert-butyl hydroperoxide (TBHP)/S of 2.5 was heated at $80^{\circ} \mathrm{C}$ and stirred at 400 rpm followed by addition of $0.12 \mathrm{~g}$ of catalyst. The reaction products were analyzed by gas chromatography (Young Lin ACME $6000 \mathrm{GC}$, Korea) equipped with a PFPD (Pulsed Flame Photometric) detector.

\section{Results and Discussion}

X-ray powder diffraction patterns of the calcined TS-1 samples prepared are shown in Fig. 1. All the TS-I samples were highly crystalline. showing the identical characteristic peaks corresponding to the zeolite MFI structure.

The UV-Vis spectra of the samples $(\mathrm{Ti} / \mathrm{Si}=0.01)$ are shown in Fig. 2. The spectra of the conventional TS-I sample (c) show an absorption band around $210 \mathrm{~nm}$. which corresponds to tetrahedral Ti(IV) coordination species in the framework. The absence of a shoulder at $260-270 \mathrm{~nm}$ corresponding to oligomeric Ti species and 330 - $350 \mathrm{~nm}$ peak corresponding to anatase phase in the UV-Vis spectra suggests that the sample is essentially free from extra-framework Ti species. The TS-1 samples prepared using carbon templates (a) and (b). on the other hand exhibited a trace of oligomeric Ti species near 260 nn. The UV-Vis spectral quality for the TS-1 samples prepared with carbon templates deteriorated further with an increasingly visible shoulder at $260 \mathrm{~nm}$ when the samples were prepared with the higher amount of titanium in Ti/Si mol ratio of 2 (not shown). It seems the presence of the heterogeneous carbon

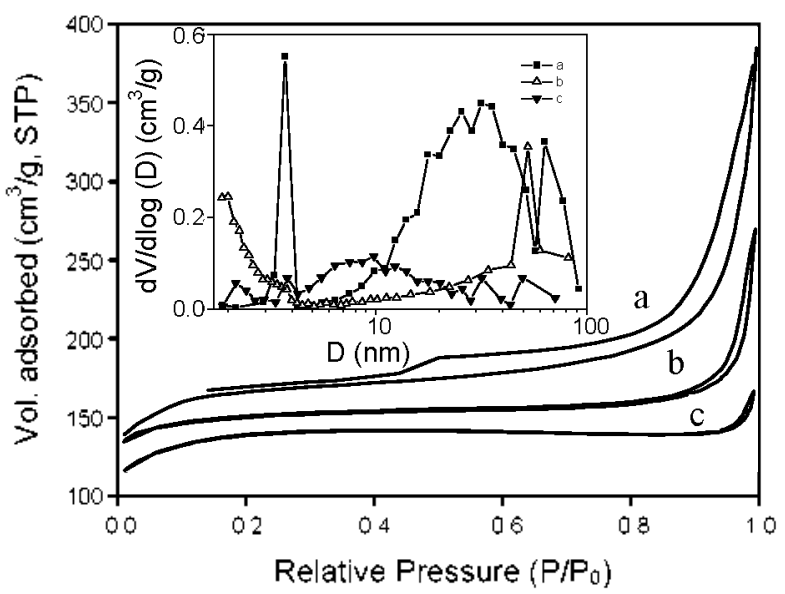

Figure 3. Nitrogen adsorption/desorption isotherms and pore size distribution curves obtained from the desorption branch by the B.JH method (inset) of (a) TS-1 synthesized with CMK-3, (b) TS-l synthesized with carbon black, and (c) conventional TS-1 
Table 1. 'Iexilural properties of the '[S-1 samples prepared

\begin{tabular}{|c|c|c|c|c|c|c|}
\hline Sample & $\begin{array}{c}\text { Teinplate } \\
\text { source }\end{array}$ & $\begin{array}{c}\mathrm{V}_{\mathrm{mks}} \\
\left(\mathrm{cm}^{\prime} / \mathrm{y}\right)^{\prime \prime}\end{array}$ & $\begin{array}{c}\mathrm{V}_{\text {Mlisio }} \\
(\mathrm{cm} / \mathrm{g})^{j}\end{array}$ & $\begin{array}{l}\mathrm{D}_{\mathrm{mls} s \mathrm{u}} \\
(\mathrm{nm})^{k}\end{array}$ & $\underset{\left(\mathrm{m}^{2} / \mathrm{g}\right)^{\prime \prime}}{\mathrm{S}_{\mathrm{cu}}}$ & $\begin{array}{c}\mathrm{S}_{\mathrm{B}: \mathrm{I}} \\
\left(\mathrm{m}^{2} / \mathrm{g}\right)^{k}\end{array}$ \\
\hline & & 0.12 & 0.31 & 14. & 110 & 388 \\
\hline neso-TS-1 & $\begin{array}{l}\text { Carb } \\
\text { black }\end{array}$ & 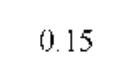 & 0.14 & 6.8 & 106 & 44 \\
\hline onv-TS-1 & . & 0.16 & 0.07 & - & 121 & 428 \\
\hline
\end{tabular}

"Calculated by the t-plot method. "Calculated by the BJHI method (desorption). "Calculated by the BET method.
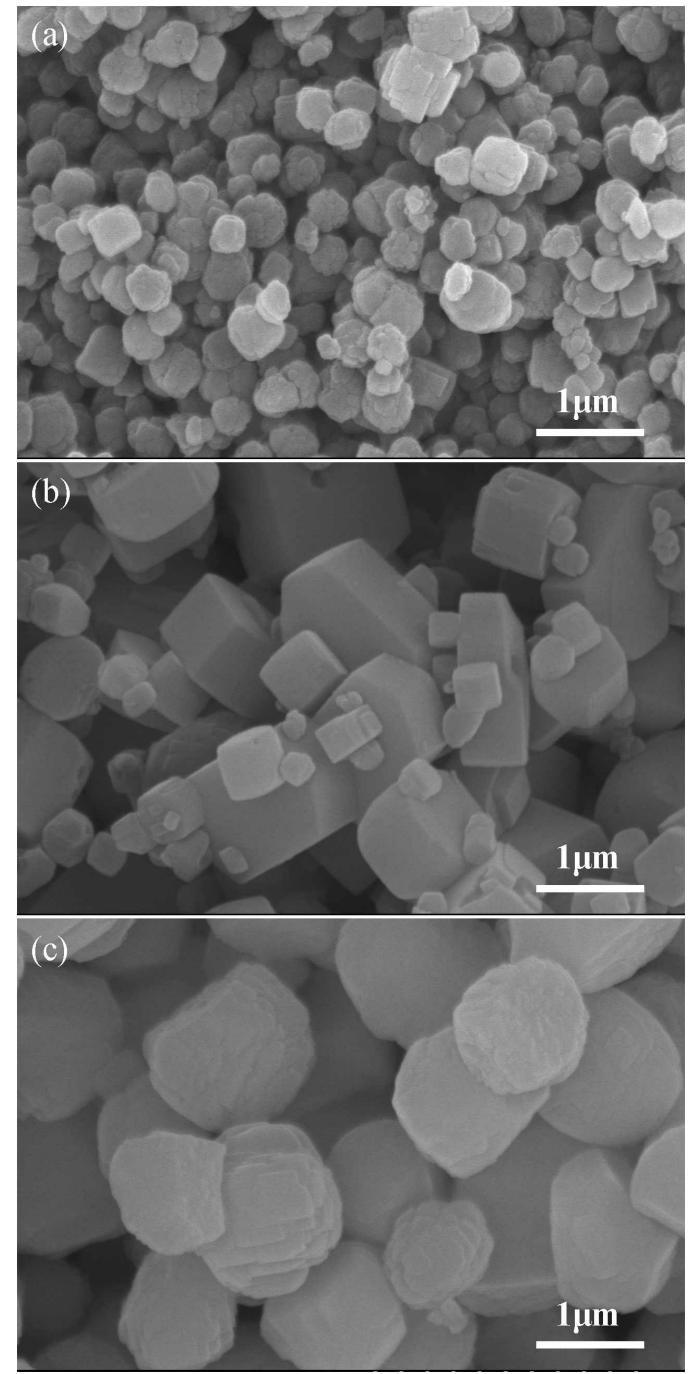

Figure 4. SEM images of (a) TS- 1 synthesized with CMK-3, (b) TS-1 synthesized with carbon black, and (c) conventional TS-1.

phase in the substrate mixture inhibits the uniform mixing of titanium and silicon alkoxide precursors during the synthesis of TS-1.

rig. 3 shows the nitrogen adsorption-desorption isotherms of the [S-1 samples after removing the carbon templates by calcination. The isotherms of TS-1 synthesized with CMK-3 (a) and carbon black (b) exhibited a hysteresis loop at relative pressures ligher than $P / P_{i f}=0.4$, clearly indicating the existence of inesopores. ${ }^{21}$ The BE"I surface areas, t-plot extemal surtace areas, pore volumes and the B.II average mesoporous sizes are given in Table $\mathrm{I}$. Whilst the micropore volumes estimated by the $t$-plot method for the three TS- 1 samples are reasonably close to one another. TS-1 synthesized with CMK-3 has the largest mesopore volume $\left(0.31 \mathrm{~cm}^{3} / \mathrm{g}\right)$ over the conventional $\mathrm{TS}-1\left(0.07 \mathrm{~cm}^{3} / \mathrm{g}\right)$ and has a significantly large average pore size. TS-I synthesized with carbon black also has shown a mesopore volume $\left(0.14 \mathrm{~cm}^{3} / \mathrm{g}\right)$ accompanied by the average pore size in the mesopore range associated with textural mesoporosity. The pore size distribution curves of the TS-l catalysts prepared were shown in the inset of rig. 3. The [S-] synthesized witl CMK-3 shows a narrow peak centered at $3.7 \mathrm{~nm}$ and broad range of pores distributed between $101080 \mathrm{~nm}$. On the other hand the TS-l synthesized with carbon black exlibited a bimodal pore size distribution; one in the range of 1.8 to 3 $\mathrm{nm}$ and the other 40 to $60 \mathrm{~nm}$. As expected, the conventional TS-I shows negligible mesopore volume. This analysis of pore size distribution shows that mesopores are successfully created by removing the carbon templates by calcination, but a small portion of macropores were also detected.

Fig. 4 shows the scanning electron microscopy (SEM) images of TS-1 samples after removal of the carbon templates. All TS-1 samples appear to be highly crystalline witl no amorphous phases detected on their external surfaces. The crystal sizes of TS- 1 catalysts as determined from SEM were ca. $0.2-0.3 \mu \mathrm{m}$ for mesoporous TS-I with CMK-3.0.2 - $1.2 \mu \mathrm{m}$ for mesoporous TS-I with carbon black, and $0.3-0.4 \mu \mathrm{m}$ for conventional TS-I, respectively. It is surprising that we could have TS-1 with smaller particle size than the conventional sample using CMK-3 templates, which will prove beneficial in licuid phase catalytic reactions involving large organic molecules due to their shorter diffusion path. We are speculating that the CMK-3 particles could have acted as a seed for TS-1 nucleation. TS-1 with carbon black, on the other hand, produced a bimodal distribution of particle size, which may be a consequenee of the relatively wide particle size distribution in the carbon black, N762 (Degussa) as mentioned earlier.

Transmission electron microscopy (TEM) was attempted to visualize the actual nanoporous structure of the TS-1 samples prepared, and Fig. 5 shows the corresponding TEM inages. Whilst it was difficult to make a clear observation of the mesopores created by carbon template as was reported by others, ${ }^{16.17}$ we could locate several grey spots of irregular mesopores in the TS-1 samples synthesized with carbon templates in (a) and (b), which were absent in the conventional TS-] sample shown in (c).

Epoxidation of allylchloride (ALC) was chosen as a probe reaction to compare the catalytic properties of the TS-l samples prepared: $A L C$ is a sulliciently small organic molecule that call be accommodated inside the 10-membered ring pores of the conventional microporous TS-l. As shown in Table 2 , conventional TS-1 showed the highest AI .C conversion ( $21.7 \%$ ) and mesoporous TS-I catalysts exhibited a little lower catalytic activitics than conventional TS-1; TS-1 prepared with CMK-3 (18.7\% ALC conversion) was somewhat better in calalylic perlormance than the TS-1 prepared with carbon black $(17.5 \%)$. We believe the differences in catalytic activitics are caused by the minor differences in lij states mentioned in Fig. 2 

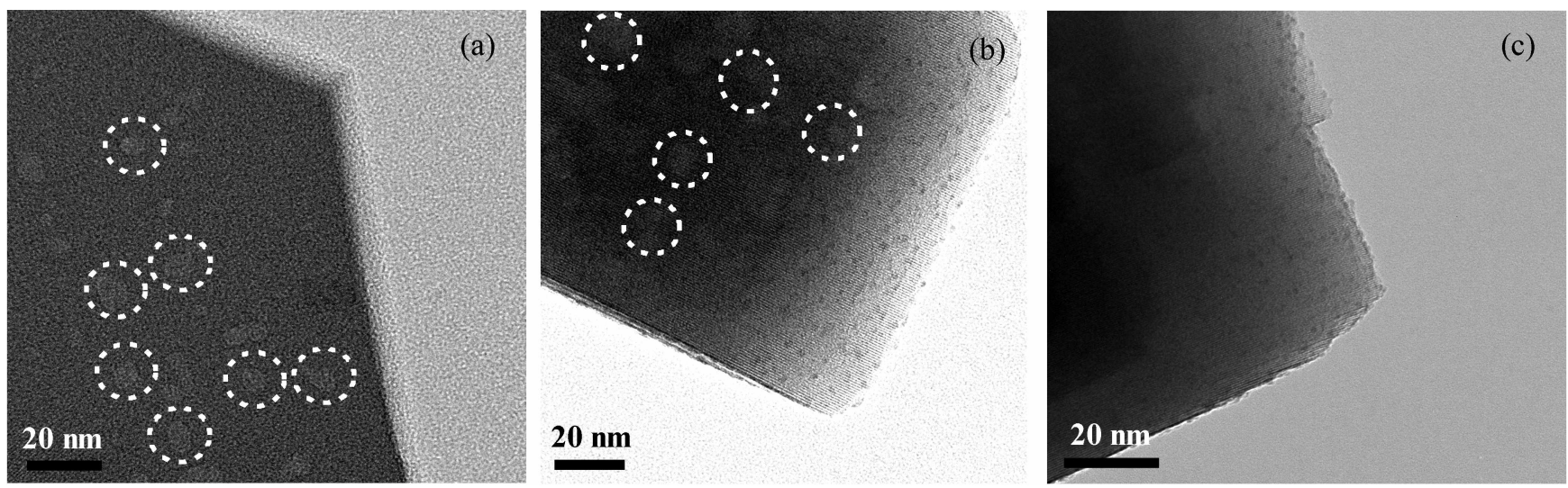

liggure 5. IT:M images of (a) IS-1 synthesized with CMK-3. (b) IS-1 sythesized with carbon black. and (c) conventional IS-1 (The circles in figures (a) and (b) indicale the regions of meso/macro pores).

Table 2. Catalytic activitics of the TS-1 samples prepared in ally lehloride epoxidation using $\mathrm{H}_{2} \mathrm{O}$

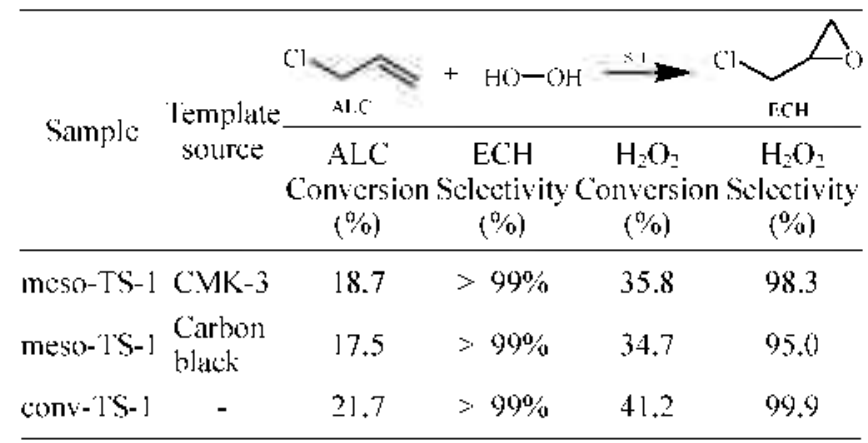

earlier, since it is known that tetrahedral $\mathrm{Ti}$ sites being more catalytically active than the oligomeric ones in TS-1. All TS-I catalysts showed satisfactory $\mathrm{H}_{2} \mathrm{O}_{2}$ selectivities: $98.3 \%$ for TS-1 synthesized with CMK-3, 95.0\% for TS- 1 synthesized with carbon black, and $99.9 \%$ for conventional TS-1. Product selectivity to epichlorohydrin (ECH) was close to $100 \%$ with only trace amounts of side products such as dichlorohydrin or 3-chloro-1,2-propandiol detected.

Finally, oxidative desulfurization of DBT and 4,6-DMDBT with tert-butyl hydroperoxide as oxidizing agent over the TS- 1 catalysts were conducted and the results are shown in Fig. 6 and Fig. 7, respectively. As shown in the figures, substantial enhancement in catalytic activity was achieved in mesoporous TS- 1 catalysts compared with conventional TS- 1 . More specifically, catalytic ODS activities of the catalysts varied in the following order: conventional TS- $1 \ll$ mesoporous TS- 1 with carbon black < mesoporous TS- 1 with CMK-3 for both DBT and 4,6-DMDBT. These results can be understood when we realize that the molecular dimensions of DBT $(8.0 \times 12.2$ $\left.\AA^{22}\right)$ and 4,6 -DMDBT $\left(8.7 \times 12.2 \AA^{23}\right)$ are signiticantly larger than the pores of conventional TS-1 zeolite $(5.6 \times 5.3 \hat{A})$. Therefore, it is reasonable to assume that molecules like DBT and 4,6-DMDBT cannot have an access to the redox-active sites located inside the pores of conventional TS- 1 , and the inproved catalytic activities of the mesoporous TS-1 catalysts must be attributed to their improved diffusion properties compared with conventional TS-1. In addition, mesoporous TS-1 prepared

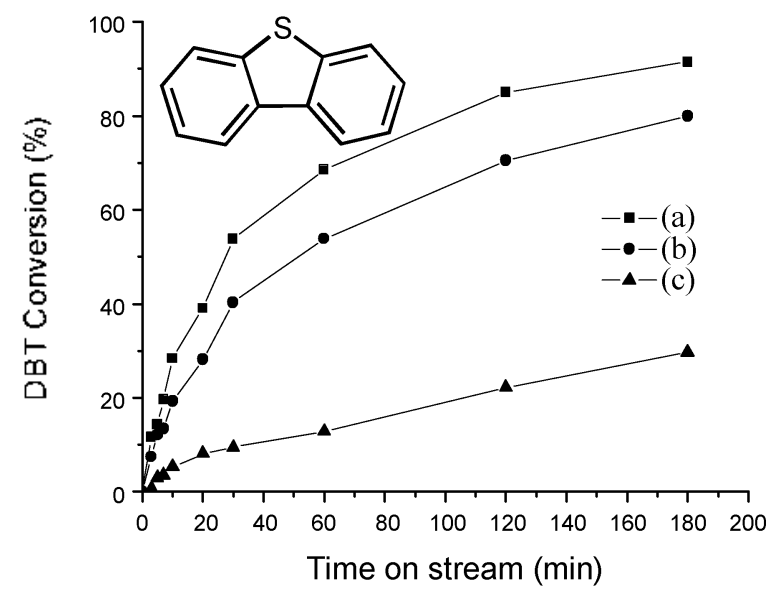

Figure 6. Calalytic oxidation of I)|3I using TI3IIP as an oxidanc by (a) TS-I synthesized with CMK-3. (b) TS-1 synthesized with carbon black. and (c) conventional TS-I.

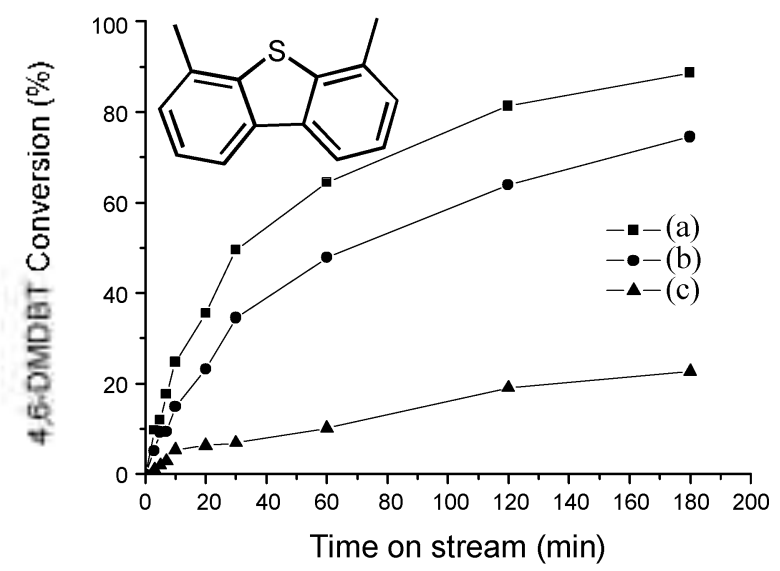

lingure 7. Calalytic oxidation of 4.6-I)MI 231 using Tl3H IP as an oxidant by (a) IS-1 synthesized iz ith CMK-3. (b) IS-I synthesized with carhon black. and (c) conventional TS-I.

using CMK-3 produced better catalytic performances than the one prepared using carbon black, since the former has the larger mesopore volumes as well as the larger average pore diameters in TS-1. In addition, smaller particle size of the 
TS-1 prepared with CMK-3 will also be usefil for the reactions due to the shorter diffusion path of the reactants.

As shown in Fig. 6 and Fig. 7. conventional TS-1 still produced significant conversions of $29.6 \%$ for DBT and $22.7 \%$ for 4.6-DMDBT after $3 \mathrm{~h}$ reaction. Apparently, ODS reaction can also take place at the catalyst extemal surfaces as well as inside the pores of TS-I catalysts.

\section{Conclusions}

Mesoporous TS-1 catalysts were prepared using CMK-3 and carbon black as templates. The sy nthesized mesoporous TS-1 catalysts were found to exhibit substantially enhanced catalytic activities than a conventional microporous TS-I catalyst in the oxidative desulfurization (ODS) of bulky sulfur compounds by providing easy access of the reactants to the active redox sites. CMK-3 was proven more effective to generate mesopores in TS-1 and also resulted in smaller particle size useful in liquid phase ODS reactions.

Acknowledgments. This work was supported by Inha University (2009). Experimental support by Dr. K. E. Jeong from KRICT is greatly appreciated.

\section{References}

1. US EPA, regulatory announcement: Heavy-Duty Engine and Vehicle Standards and Highway Diesel Fuel Sulfur Control Requirements, December 2000.

2. Liotta, F. . : Han, Y. Z. Production of Lilra-Low Sulfur Fuels by Selective Hodroperoxide Oxidation: NPRA AM-03-23, Washington, DC, March 23-25, 2003
3. Röthlishberger, A.; Prins, R. J. Catal. 2005, 235, 229

4. Lü, H.; Gao, T.; Tiang, Z, Ting, F.: Yang, Y,; Wang, G.; Li, C. J. Catal. 2006, 239, 369 .

5. Palomeque, J.; Clacens, J. M; Figueras, F. J. Catal. 2002, 211, 103.

6. Otsuki, S.; Nonaka, T.; Takashima. N.: Qian, W. Energu Fuels $2000,14,1232$

7. Jeong, K. E.; Chae, H. J.; Kim, U. C.; Teong, S. Y.; Ahn, W. S. Solid State Phenont. 2008, 135,89.

8. Hulea, V.: Fajula, F.: Bousquet, J. J. Catal 2001, $198,179$.

9. Kong. L.: Li, G.; Wang, X. Catal. Toda, 2004, 93,341

10. Jin, C.; Li, G.; Wang, X.; Wang, Y.; Zhao, L.; Surn, D. Microponous Hesoporous Haten: 2008, 111, 236.

11. Kong. L.: Li, G.; Wang, X. Catal. Lett. 2004, 92, 163

12. Jacobsen, C. I. H.; Madsen, C.: Houzvicka, J.: Schmidt, I.; Carlsson, A. J. Am. Chem. Soc. 2000, 122,7116.

13. Kustova, M. Y: Hasselriis, P: Christensen, C. H. Catal. Lett. $\mathbf{2 0 0 4}, 96,205$.

14. Wei, X:- Sminiotis, P. G. Microporous Mesoporons Mater. 2006, 89, 170 .

15. Egeblad, K; Kustova, M; Klitgaard, S. K.; Zhu, K.; Christensen, C. H. Hicroporous Mesoporous Mater: 2007, 101, 214.

16. Schmidt, I.: Krogh, A.: Wienberg. K.: Carlsson, A.: Brorson, M. Jacobsen, C. J. H. Chem. Commm. 2000, 2157.

17. Fang, $\mathrm{Y}: \mathrm{Hu}, \mathrm{H}$. Catal Conmm 2007, 8, 817.

18. Zhao, D; Huo, Q; Feng, T; Chmelka, B. F; Stucky, G. D. J. Ant. Chem. Soc. 1998, 120,6024.

19. Jun, S.: Joo, S. H.: Ryoo, R.: Kruk, M.; Jaroniec, M.; Liu, Z:; Ohsuna, T:; Terasaki, O. J.4m. Chem. Soc. 2000, 122, 10712.

20. Serrano, D. P.; Uguina, M. A.; Ovejero, G.; Grieken, R. V: Camacho, M. ificroporous ifoter $1996,7,309$.

21. On, D. T.: Lutic, D.: Káliaguine, S. Aficroporous Mesoporous Nater. 2001, 44, 435 .

22. Daage, M: Chianelli R. R. J. Catal 1994, $149,414$.

23. Meng, X; Wu, Y; Li, Y. J. Porous lloter 2006, 13, 365. 